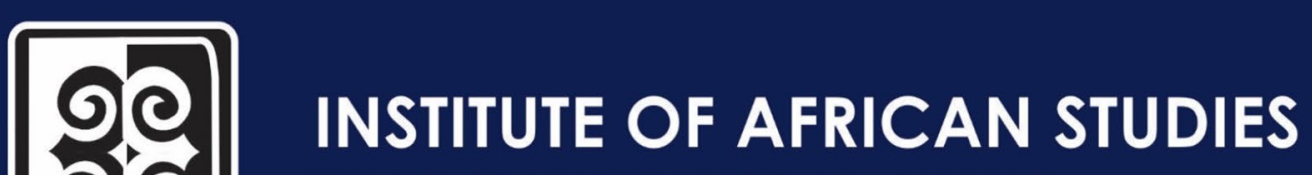 UNIVERSITY OF GHANA
}

Contemporary Journal of African Studies 2020; 7 (2): 63-78

https://dx.doi.org/10.4314/contjas.v7i2.5

ISSN 2343-6530

(C) 2020 The Author(s)

Open Access article distributed under the terms of the

Creative Commons License [CC BY-NC-ND 4.0]

http://creativecommons.org/licenses/by-nc-nd/4.0

\section{Traditional Reproductive Health and Family Planning Practices among the Dagomba}

\author{
Abukari Kwame $^{1}$ \& Pammla M. Petrucka ${ }^{2}$ \\ ${ }_{1}^{1}$ Phd Candidate, College of Graduate and Postdoctoral Studies, University of Saskatchewan, Canada \\ Author's email. abukarikwames@yahoo.com
}

2 Professor, College of Nursing, University of Saskatchewan, Canada

Author's email: pammla.petrucka@usask.ca

\begin{abstract}
This paper is a qualitative descriptive study of traditional reproductive health $(R H)$ and family planning practices among Ghana's Dagomba. The purpose of the study was to examine the Dagomba traditional knowledge of RH practices and beliefs, and their relevance in the context of modern health practices. Data for this study was gathered through qualitative methods, including individual in-depth interviews, focus group discussions, and the use of a qualitative questionnaire among 37 participants. Thematic analysis was undertaken. In examining the Dagomba traditional knowledge of $\mathrm{RH}$ practices, it was recognized that the concept of RH extends across the life continuum, reaching beyond the sexually active adult population. The RH practices are based on the Dagomba health beliefs and value systems regarding sexuality and the body's functioning. The Dagomba's health philosophies and practices regarding pregnancy, delivery, breastfeeding, and sexuality have public and preventive health functions, including conflicting positions. The typical traditional $\mathrm{RH}$ and FP practices include abstinence, rhythm, prolonged breastfeeding, and postpartum abstinence. Conclusion: We posit that when traditional knowledge of RH is examined critically by modern health experts, it could help us understand why people from different cultures have varying interpretations and uptake of modern RH practices. Thus, we invite biomedical practitioners to be culturally sensitive and incorporate relevant knowledge of traditional $\mathrm{RH}$ practices into their current health education efforts.
\end{abstract}

Keywords: Traditional knowledge, reproductive health, sexuality, Dagomba, Ghana 


\title{
Traditional Reproductive Health and Family Planning Practices among the
}

\section{Dagomba}

\author{
Abukari Kwame, Pammla M. Petrucka
}

\begin{abstract}
This paper is a qualitative descriptive study of traditional reproductive health $(\mathrm{RH})$ and family planning practices among Ghana's Dagomba. The purpose of the study was to examine the Dagomba traditional knowledge of $\mathrm{RH}$ practices and beliefs, and their relevance in the context of modern health practices. Data for this study was gathered through qualitative methods, including individual in-depth interviews, focus group discussions, and the use of a qualitative questionnaire among 37 participants. Thematic analysis was undertaken. In examining the Dagomba traditional knowledge of $\mathrm{RH}$ practices, it was recognized that the concept of $\mathrm{RH}$ extends across the life continuum, reaching beyond the sexually active adult population. The RH practices are based on the Dagomba health beliefs and value systems regarding sexuality and the body's functioning. The Dagomba's health philosophies and practices regarding pregnancy, delivery, breastfeeding, and sexuality have public and preventive health functions, including conflicting positions. The typical traditional RH and FP practices include abstinence, rhythm, prolonged breastfeeding, and postpartum abstinence. Conclusion: We posit that when traditional knowledge of $\mathrm{RH}$ is examined critically by modern health experts, it could help us understand why people from different cultures have varying interpretations and uptake of modern $\mathrm{RH}$ practices. Thus, we invite biomedical practitioners to be culturally sensitive and incorporate relevant knowledge of traditional $\mathrm{RH}$ practices into their current health education efforts.
\end{abstract}

Keywords: Traditional knowledge, reproductive health, sexuality, Dagomba, Ghana

\section{Résumé}

Cet article présente une étude descriptive qualitative des pratiques traditionnelles de santé reproductive (SR) et de planification familiale chez les Dagomba du Ghana. Le but de l'étude était d'examiner les connaissances traditionnelles des Dagomba en matière de pratiques et de croyances de SR et leur pertinence dans le contexte des pratiques de santé modernes. Les données de cette étude ont été recueillies à travers des méthodes qualitatives, notamment des entretiens individuels approfondis, des discussions de groupe et l'utilisation d'un questionnaire qualitatif auprès de 37 participants. Une analyse thématique a été entreprise. En examinant les connaissances traditionnelles des Dagomba sur les pratiques de santé reproductive, il a été reconnu que le concept de santé reproductive s'étend sur tout le continuum de vie, au-delà de la population adulte sexuellement active. Les pratiques de santé reproductive sont basées sur les croyances sanitaires et les systèmes de valeurs des Dagomba concernant la sexualité et le fonctionnement du corps. Les philosophies et pratiques sanitaires des Dagomba relatives à la grossesse, l'accouchement, l'allaitement et la sexualité ont des fonctions de santé publique et préventive, y compris des positions contradictoires. Les pratiques traditionnelles typiques de santé reproductive et de PF comprennent l'abstinence, le rythme, l'allaitement prolongé et l'abstinence post-partum. Conclusion: Nous soutenons que l'analyse critique des connaissances traditionnelles en matière de santé pourrait nous aider à comprendre pourquoi les personnes issues de

\section{https://dx.doi.org/10.4314/contjas.v7i2.5}

Abukar i Kwame (abukarikwames@yahoo.com) is currently a PhD candidate in Interdisciplinary Studies at the College of Graduate and Postdoctoral Studies, University of Saskatchewan with interest in language use in nurse-patient interaction and patient rights. Mr. Kwame holds two M.Phil degrees, one in Indigenous Studies and the other in English Linguistics. His research interest areas include language use in social interaction, First/Second language acquisition, traditional knowledge, indigenous research methodology, and qualitative research methods. This study was conducted at the time Mr. Kwame was an MPhil student at the Arctic University of Norway, Tromso.

Pammla M. Petrucka (pammla.petrucka@usask.ca) is a professor in Nursing at the College of Nursing, University of Saskatchewan. Prof. Petrucka has international research experience with many of her graduate students coming from Africa, Asia, and the Caribbean. She has published extensively in the field of nursing. Her research interests are vast, including child and maternal health, Indigenous peoples' health, global health, and vulnerable populations, with extensive experiences in qualitative research, and indigenous research methodologies. Prof. Petrucka is also co-editor of the BMC Nursing journal and a reviewer for many other academic journals. 
différentes cultures ont des interprétations et des adoptions différentes, quant aux pratiques modernes de santé reproductive. Ainsi, nous invitons les praticiens biomédicaux à être sensibles à la culture et à intégrer les connaissances pertinentes des pratiques traditionnelles de santé reproductive dans leurs efforts actuels d'éducation sanitaire.

Mots-clés : Connaissances traditionnelles, santé reproductive, sexualité, Dagomba, Ghana

\section{Introduction}

Traditional reproductive health $(\mathrm{RH})^{1}$ and family planning (FP) practices are historical, unique to different societies and cultures, and are often in use for maternal and child health promotion (Helman, 2007; Raman et al., 2016; Rabiu \& Rufai, 2018). The International Conference on Population and Development (1994) defined RH as "a state of complete physical, mental and social well-being, and not merely the absence of disease or infirmity, in all matters related to the reproductive system and to its functions and processes" (cited in World Health Organization [WHO], 2003, p. 7). Although fairly comprehensive, this definition ignores the spiritual dimension of health, in general, and $\mathrm{RH}$ in particular, which is recognized in most societies as important, given that several spiritual practices and rituals are reported as enhancing $\mathrm{RH}$. In most cultures, traditional RH practices--including spiritual and ritual ceremonies--are performed around pregnancy, childbirth, and breastfeeding for the safety of both the infant and mother (Aborigo et al., 2015; Helman, 2007; Mairiga et al., 2012; Raman et al., 2016).

In Nigeria, traditional RH practices abound. For instance, Jinadu and Ajuwon (1997) and Jinadu, Olusi, and Ajuwon (1997) found that among Yoruba women, waistbands, rings, herbal soup, and incisions with herbal powers were used as traditional FP methods to regulate pregnancy. Most recent studies among women of childbearing age in Kano (Rabiu \& Rufai, 2018), among the Kanuri people (Mairiga et al., 2012), and women of Ekiti State (Durowade et al., 2017) have all reported the use of traditional RH practices including charms, herbal medicine, the rhythm method, postpartum abstinence, and cervical mucus method. Bove and Valeggia (2009), Raman et al. (2016), and the WHO (2007) have also provided global data on these practices to highlight the relevance of culture, traditional beliefs, and values to $\mathrm{RH}$.

In Ghana, different cultural groups and societies have diverse traditional RH practices informed by their belief systems and worldviews on health, illnesses, and social relations. For example, among the Kasena-Nankana people, it is strongly believed that sex during the postpartum period affects breastmilk quality and infant health (Awedoba, 2002). Furthermore, Aborigo et al. (2012) and Hill et al. (2014) found that among the Kasena-Nankana, there are traditional practices to promote good infant feeding and increase breastmilk among lactating mothers. These studies have observed that the Kasena people have a time-honored ritual of determining breastmilk quality and its safety for the infant among first-time mothers. Other studies in Northern Ghana on traditional maternity care (Bassoumah \& Adam, 2018) and child upbringing practices (Dove, 2010) have revealed that taboos on food and behaviours, ritual performances, sacrifices, and injections of herbal medicines are common at the prenatal, intrapartum. and postnatal stages. For instance, Dove (2010) found that various traditional remedies, rituals, and taboos are performed across different cultures in Northern Ghana to aid in pregnancy health, safety of the unborn child, and for easier and safer delivery.

Although these traditional $\mathrm{RH}$ practices were used in the past and are currently being used, as reported in several studies, including a national demographic survey (Ghana Health Service [GHS], 2010; Ghana Statistical Services [GSS], GHS, and ICF International, 2015), some traditional RH practices (e.g., female genital mutilation) have been outlawed for their negative consequences on health. Furthermore, researchers have criticized other traditional RH practices on the basis of hygiene, safety, and efficacy. For example, Bassoumah and Adam (2018) argued that using fundal massaging with a hot towel on the abdomen of women who just delivered or tying a piece of cloth around their abdomen after spontaneous delivery of the placenta defies WHO recommendations. Also, Aborigo et al. (2012, p. 6) noted that among the Kasena, "colostrum from first-time mothers is often tested for bitterness by putting ants in it". It signifies that the breastmilk is bitter and not safe for the infant to take if the ant dies. This process could lead to delays in initiating breastfeeding, which also deviates from modern breastfeeding recommendations.

Research has shown that despite the availability of modern FP methods and increased knowledge about these services, awareness of these methods and services does not translate into actual or proper usage (Ajayi et al., 2018; Durowade et al., 2017; Kyilleh et al., 2018). Traditional beliefs and religious values, spousal disapproval, fears of side effects of modern contraceptives, and attitudes of some healthcare professionals are

\footnotetext{
${ }^{1}$ Abbreviations: BMP - Biomedical Practitioner; FP - Family Planning; HSC - Healthcare Service Consumer; $\mathrm{MOH}$ - Ministry of Health ; RH - Reproductive Health; TMP - Traditional Medical Practitioner; UNESCO - United Nations Educational, Scientific, and Cultural Organization; UNICEF - United Nations International Children's Emergency Fund
} 
reported as barriers to the uptake of modern FP methods (Cox et al., 2013; Craymah et al., 2017; Etokidem et al., 2017).

In light of the above, our aim was to explore the traditional $\mathrm{RH}$ practices among the Dagomba for two reasons. Firstly, there is no comprehensive study that examines the traditional RH practices of Dagomba. Secondly, little is known about the relevance of the traditioanl Dagomba RH practices in the modern context, given the pressure to abandon many traditional ways of life due to increased education and urbanization levels. Therefore, we explored the RH practices of the Dagomba using two research questions, thus: what are the traditional $\mathrm{RH}$ and FP practices of the Dagomba? and how relevant are these in promoting maternal and child health in the modern context?

\section{Reproductive health and family planning: An overview.}

Reproductive health and FP programs are generally used in population, maternal, and child health, emphasizing women and their fertility concerns. Through the efforts of politicians, development experts, epidemiologists, and academic researchers, the focus has emphasized designing of policies and obtaining evidence on how modern FP methods and RH strategies can regulate fertility rates, stabilize population growth, and improve maternal and child health outcomes. For instance, Cleland et al. (2006) observed that when FP is promoted in high birth rate countries, it potentially reduces poverty, hunger, and maternal and infant mortalities. Thus, RH and FP policies are often targeted at reducing fertility and infant and maternal mortality rates, with women of reproductive ages being the target population. In many developing countries, there has been a slow but increasing involvement of men, primarily as decision-makers, especially in FP and contraceptive usage (Akafuah \& Sossou, 2008; Berhane et al., 2011; Cox et al., 2013; Mutiba-Ngoma, 2010; Opoku \& Kwaununu, 2011).

Further, the literature is replete with works on modern FP methods and their usage among men and women; the role of FP in fertility regulations; and challenges relating to current contraceptive usage (Berhane et al., 2011; Cleland et al., 2006; Craymah et al., 2017; Kyilleh et al., 2018). Ofosu-Amaah (2005) reported that, although $22 \%$ of married women used contraception methods, only $13 \%$ of all women used a modern contraception form in Ghana. Moreover, Ghana's moderen contraceptive prevalence regressed slightly between 2011 (23\%) and 2014 (22\%), with total unmet needs for the modern FP methods increasing from $26 \%$ in 2011 to $30 \%$ in 2014(Ministry of Health [MOH], 2015).

Most studies in Ghana are focused on modern FP, spousal communication, or gender-specific attitudes towards contraceptive usage (Akafuah \& Sossou, 2008; Cox et al., 2013; Opoku \& Kwaununu, 2011). For instance, Akafuah and Sossou (2008) examined attitudes of Ghanaian men towards FP, revealing lack of knowledge and sociocultural factors as contributing to the lack of male involvement in FP. In contrast, Cox et al. (2013) studied the quality of couples' relationships in Kumasi and how couples' emotional aspects affect contraceptive usage.

Similarly, Opoku and Kwaununu (2011) found that, although nearly half (47\%) of Ghanaian women reported a history of contraceptive use, only $20 \%$ are current users. Also, recent studies found that, despite the availability of modern contraceptives, uptake is still low due to prohibitive cultural norms, negative attitudes of some healthcare professionals, and perceptions about the adverse effects of most modern FP methods (Craymah et al., 2017; Hill et al., 2014; Kyilleh et al., 2018). These barriers to uptake of the contemporary contraceptives have also been identified in Nigeria (Ajayi et al., 2018; Durowade et al., 2017; Etokidem et al., 2017). Despite the barriers to modern contraceptive usage, there are minimal reflections on how traditional knowledge, beliefs, and practices impact the uptake and acceptability of current reproductive health and FP practices.

Increasingly, traditional RH and FP practices have been acknowledged in many studies, especially in developing countries and among select communities, such as rural inhabitants in Ghana (Aborigo, Allotey, et al., 2015; Aborigo, Moyer, et al., 2012; Adongo et al., 1997), Nigeria (Mairiga et al., 2012; Rabiu \& Rufai, 2018), and among several cultural groups in Asia (Raman et al., 2016). Discussions on relevance, prevalence, and influencers for the utilization of traditional and/or modern FP methods have been highly variable. Bertrand, Mangani, Mansilu, and Landry's work in Bas Zaire found that $95 \%$ of women had some knowledge of traditional FP methods. While most women had used at least one form of traditional FP ( $50 \%$ usage in urban and $62 \%$ in rural areas), there remained low rates of use of modern FP ( $11 \%$ urban and $7 \%$ rural) (Bertrand et al., 1985), despite high levels of knowledge of such practices. Other studies have demonstrated the persistence of traditional RH and FP knowledge in sub-Saharan Africa about HIV/AIDS management (Homsy et al., 2004; Liddell et al., 2005).

Researchers have identified the need to explore the impacts of culture, belief systems, and gender relations on the use of modern contraceptives and FP methods (Bawah et al., 1999; Hill et al., 2014; Jaffre \& Suh, 2016; Raman et al., 2016). For instance, Jaffre and Suh (2016) have argued that there is a need for researchers on $\mathrm{RH}$ and FP to examine sociocultural practices, power dynamics, and gender relations in the use of modern contraceptives. In contrast, Raman et al. (2016) called for examining culture's roles in shaping RH behaviours and practices in context. 
Additionally, Helman (2007) noted that traditional FP and contraception need to be understood in the context of people's beliefs about the functioning of their bodies concerning sexuality, fertility, and pregnancy. Further, she maintained that regardless of effectiveness, we can no longer ignore that traditional practices are often mainstream and impact the likelihood of uptaking modern contraceptives and FP methods. As a result, there is an imperative to acknowledge, research, and evaluate these traditional RH and FP practices, their relevance, and how they can inform the context and usage of modern contraceptives.

When traditional RH practices (and the health beliefs, cultural values, and norms influencing that) are integrated into health policy, it may broaden perspectives on $\mathrm{RH}$. This paper considers the Dagomba traditional knowledge of $\mathrm{RH}$ practices and beliefs, and their relevance within the context of modern health. Findings potentiate the necessary dialogues that may bring essential and appropriate traditional knowledge systems and practices into health promotion campaigns for modern contraceptives and FP. Although few similar studies have examined this topic among the Kasena-Nankana and other cultures in Northern Ghana (Adongo et al., 1997; Awedoba, 2002; Bawah et al., 1999), no prior study of this type has been found respecting the traditional RH and FP of the Dagomba in Northern Ghana. Moreover, a larger part of Dagbon is rural with high illiteracy rates, poor access to healthcare facilities, and cultural norms and values that may constrain the rural populace's use of modern contraceptives and FP methods. Hence, this descriptive study queries: What are the traditional RH and FP practices among the Dagomba? and how relevant are these practices in the modern health context?

\section{Dagbon: Setting and Sources}

Dagbon is a traditional area in Northern Ghana, established around the fourteenth century AD (Tonah, 2012). This multiethnic region is divided into Eastern Dagbon (Yendi and its surroundings) and Western Dagbon (Tamale and its surroundings) with a range of migrants (Mamprusi, Gonja, Dagaba, Ewe, Fulani, and Akan speaking). However, the area is predominantly occupied by over two million Dagomba people, one of the largest ethnic groups in the Northern Region (Ghana Statistical Services [GSS], 2013), who are traditionally engaged in small scale agriculture and livestock rearing.

The Dagomba have a traditional governance system under the leadership of the paramount king, Yaa$\mathrm{Naa}$, and several other levels of authorities below (Tonah, 2012). The Dagomba people practice polygamy and a patrilineal system of inheritance. The majority of Dagomba are Muslims (over $60 \%$ ), with the remaining being Christians or traditional religious practitioners (GSS, 2013). Hence, most of the festivities, funerals, and marriage rites and cultural practices in Dagbon are heavily influenced by Islam (Abdul-Hamid, 2010).

Data for this descriptive ethnographic study were obtained from multiple sources. Data collection occurred from June to August in 2015 and 2016 in Yendi, Sunsung, Paansiya, Pelaaya, and Gukpegu. Data used in this article was part of a more extensive study on traditional medicine and healing practices among the Dagomba. Additional data were collected on the traditional RH and FP practices in a follow-up study on Islamic healing practices among the Dagomba in 2016. During that study, issues on traditional RH practices came up and were explored. Purposive sampling was used to access a total of 37 participants, 14 females and 23 males, consisting of three traditional birth attendants (TBAs), ten traditional medical practitioners (TMPs), ten biomedical practitioners (BMPs), and 14 health service consumers (HSCs).. The majority of the participants were males due to the number of traditional healers who participated in the study. Only two healers were females; the rest were males. The age range of the participants was $20-90$, with a mean age of 49 years. Fourteen (all the biomedical practitioners (BMPs), three traditional medical practitioners (TMPs), and one health service consumers (HSC) participants had some level of formal education, while the remaining particicipants did not have any formal education. Regarding their marital status, three were widowed, four were single, and the rest were married. The average age of marriage for men was around 29.5 years, and 24.5 years for women. Most of the participants were Muslims ( $n=32$ ). Four were Christians, and one was a Traditional religious practitioner. Except for four of the BMPs, the remainder of the participants were Dagomba.

Prior to participation, the study's purpose was explained to each participant, and voluntary consent was obtained before data collection commenced. Primary data was gathered through in-depth individual interviews with the TMPs and TBAs, two focus group discussions with the HSC ( 7 participants in each group), and the use of open-ended qualitative questionnaire with the BMPs. We collected data in five communities within the Yendi Municipality. Also, personal observations were made on healing practices, where extensive field notes were taken.

In all, 13 individual interviews and two focus groups were conducted among the traditional healers and TBAs, while ten completed questionnaires were returned from the BMPs. Several hours were also spent during observation of specific healing practices. The interviews and focus group discussions (average length of meetings being 54 minutes) were audio-recorded in Dagbani with the participants' consent. The recordings were transcribed verbatim, translated into English, and verified by participants for accurateness. Transcripts were then manually coded and thematically analyzed (Lacey \& Luff, 2009; Miles et al., 2013). Braun and Clarke's (2006) 
and Clarke and Braun's (2013) analytical approaches to thematic analysis were employed, where data codes were clustered into categories and further grouped into themes.

To enhance the trustworthiness of the results, our preliminary findings were submitted to member checks among some participants. The primary data sources were also compared continuously to identify the various themes and concepts which formed the main results. Other secondary data sources (e.g., journal articles, books, reports) that focused on $\mathrm{RH}$, FP, or traditional knowledge systems were used. The primary study was approved by the Norwegian Social Science Data Services (NSD) (Ref: 43718 / 3 / MSI) and the Yendi Municipal Hospital.

\section{Theorising reproductive health in Dagbon}

Lay theories of health and illness (Kleinman, 1980; see also Helman, 2007; Bowling, 2009), and Becker and Rosenstock' s (1987) Health Belief Model (HBM) (cited in Bowling, 2009) formed the theoretical framework upon which analysis in this study was based. Lay theories of health and illness consider broader cultural perspectives on what health and illness mean to different cultures, and what caused ill-health. The Dagomba lay theories of health and illness (Bierlich, 2000; Kwame, 2016a; 2016b) constitute their cultural understandings of what it means to be healthy or ill, the role their belief systems play in illness causal analysis and interpretation. The Dagomba theorize that health and illness lie on a continuum, with natural forces and spiritual beings constituting causal illness elements. The Dagomba believe that some illnesses are innate to the body systems, while others come into the body from the environment. Hence, the natural, social, and supernatural worlds are constitutive of sources of illness. Individuals' susceptibility to illnesses is based on their age, head, and blood quality.

Becker and Rosenstock's (1987) HBM proposes that people's behaviors concerning health and illness are influenced by their perceptions of the severity of an illness, their susceptibility to the illness, and the cost and benefits incurred in undertaking therapeutic action (cited in Bowling, 2009). Further, Gauvin and BelangerGravel (2017, p. 69) argue that the HBM assumes that "individuals hold different sets of beliefs about a disease or health threat $\cdots$ and that these beliefs are likely to influence the uptake of preventive [health] measures." The model further argues that self-efficacy and individual beliefs and actions propel them towards preventive health measures. Moreover, the model emphasizes the perceived severity, susceptibility, benefits, and barriers as some psychological factors considered when predicting and explaning people's behaviour regarding health decision-making (Gauvin \& Belanger-Gravel, 2017).

Thus, the Dagomba cultural practices, beliefs, norms, and values relating to health and illness, in general, and sexuality and $\mathrm{RH}$, are drawn upon to examine traditional $\mathrm{RH}$ practices. The perceived benefits and consequences for observing or resisting traditional $\mathrm{RH}$ and FP practices are noted.

\section{Dagbon concepts of reproductive health}

Reproductive health is part of the Dagomba general understanding of health, which describes alaafee (good health) as having suhudoo (a peace of mind) and being in a state of balance between self, society, and the spiritual world (Kwame, 2016a; 2016b). The concept of good health goes beyond an individual's subjective state to encompass everything within the individual and his/her surroundings. Having alaafee includes the ability to provide for family and one's dependants, since poverty is a significant source of worry and a cause of lack of suhudoo and often seen as fara doro (poverty illness)

By extension, RH (do?im alaafee) means that a person is in a state of balance within the selfreproductive system and all relations connected to it. The root word, do?i, has a meaning extension that translates to 'give birth to'. It also means all people related by birth (the family and beyond) as in $N$-do? im (my family). The concept of $\mathrm{RH}$ is therefore connected to childbirth and all processes and practices that precede and or follow the delivery. To conceptualize $\mathrm{RH}$, one participant noted:

When a woman carries a pregnancy to the end and delivers successfully at home without any problems, then we can say there's do? im alaafee. Both the mother and the child should be safe after delivery. You see, when a woman delivers at the hospital and stay there for days due to complications, we can't wholeheartedly say there is alaafee. Because when you inform others about the delivery, they may want to know how both mother and child are doing.

Many participants related RH to pregnancy and successful delivery at home. However, some agreed that delivering at the hospital and even with a surgical intervention could be considered as healthy delivery if there are no complications after childbirth. In the above conception of $\mathrm{RH}$, some sociocultural notions of emotional, psychological, physical, and even economic safety are implied, requiring both individuals and society to undertake some actions towards fulfilling the implied safety burden. Similar perceptions about RH, especially around pregnancy, place of delivery, infant care, and the role of grandmothers and the family, have been reported among the Kasena-Nankana (Aborigo et al., 2012; Gupta et a., 2015) and other cultural groups in Northern Ghana (Dove, 2010; Moyer et al., 2014). 
Relating $\mathrm{RH}$ to childbirth implies the need for functional reproductive systems for conception and childbearing to proceed. This perspective could explain why do? im alaafee is intuitively related to safe delivery. $\mathrm{RH}$ is, therefore, seen as a complex process that starts at birth among the Dagomba. Hence, RH practices are sophisticated, intertwined with, and influenced by cultural norms and belief systems.

According to the Dagomba lay theories of health, the concept of RH encompasses FP, in the sense of proper spacing of children. Notions of FP, about our contemporary understanding of the term, are captured in two phrases in Dagbani: do?tri gandim gandim (spacing children ages) and dop $\dot{i}$ saptsi (giving birth to a small number of children). The former was what many Dagomba practiced until a few decades ago when the latter was also taken up, perhaps due to the influence of formal education and global diffusion of the imperatives of population control.

In the past, giving birth to many children was valued; as children were sources of the workforce, to maintain family lineage, support during old age, and, at times, social prestige (Awedoba, 2002; Gyekye, 1996; Tabong \& Adongo, 2013). Accordingly, giving birth to a small number of children was never part of the FP practices of the Dagomba. An elderly participant noted:

Ti daa ka dop'i sapisi. Hali di yi daa beni gba, ti je li': Translated literally as "we didn't have family planning (as in the practice of giving birth to a small number of children), even if it was there we don' $t$ want it." The participant added: I've lost six of my children. If I had given birth to only three or four children, I'/l be childless by now.

Therefore, past FP practices among the Dagomba were not for fertility regulation but to help proper birth spacing. Proper birth spacing was to enhance the health of both mother and child. However, the Dagomba now fully incorporated notions of having a smaller family size, expressed as do? $\dot{f}$ sar $\dot{s}$ si, which fully captures the modern sense of FP into their worldview of $\mathrm{RH}$. Studies among different cultures have shown a similar understanding of $\mathrm{RH}$ and FP from a traditional worldview, where traditional $\mathrm{RH}$ practices were more about birth spacing than having small family sizes (Awedoba, 2002; Raman et al., 2016).

\section{Knowledge of traditional reproductive health practices}

Both TMPs and HSCs had detailed knowledge and information regarding traditional Dagomba RH practices. They spoke of indigenous illnesses relating to sexuality and childbearing, while few BMPs demonstrated such knowledge. Conversely, most TMPs and HSCs had limited knowledge about modern contraceptives and FP methods, often only identifying one or two FP methods they heard about from friends, through the media, or BMPs. Many claimed they had never used modern FP methods. The media, healthcare professionals, and peers have been reported as sources of information and knowledge about modern contraceptives and FP methods (Kyilleh et al., 2018). People's awareness of these contraceptives is often low, even among the youth. Lack of knowledge about the modern contraceptives and FP methods in this study could have been due to the TMPs and healthcare consumers' low literacy rate.

On the other hand, most BMPs lacked knowledge about traditional RH practices or available traditional FP methods. Still, a few identified the exercise of a woman going back to her family after the first child as one traditional approach of regulating fertility. This knowledge context implies that public health education about modern contraceptives is usually conveyed through family members and friends, the media, and BMPs, as reflected in Ghana health survey reports (GSS, GHS, \& ICF International, 2015).

HSCs have very little knowledge about the modern contraceptives and FP methods and exhibit low interest in using them. Two reasons could contribute to this scenario. First, the participants were beyond childbearing age as many of them were above age 45 , thus complacent towards the practices (GSS, GHS, \& ICF International, 2015). Second, they lacked access to modern contraceptives, thus leaving them with the intentionality of proper spacing of children, but not reducing the number of children. Negative perceptions abound about the modern contraceptives and FP methods, including notions such as, "it makes people grow fat", "people find it hard to conceive after using the pill for long", and "some have their menses continuously". Perceptions of this nature have been reported in Ghana (Cox et al., 2013; Tabong \& Adongo, 2013), Nigeria (Ajayi et al., 2018; Durowade et al., 2017; Rabiu \& Rufai, 2018), and Burkina Faso (Rossier \& Hellen, 2014).

\section{Traditional reproductive health beliefs and practices}

Reproduction is an essential process that most societies and cultures highly value, ensuring the continuity of society and humanity. Most communities have thus placed a greater focus on this system and how it is managed and regulated. Selected traditional $\mathrm{RH}$ practices and narratives among the Dagomba are reflected herein.

\section{Pregnancy}

Pappuli (pregnancy) is an integral part of $\mathrm{RH}$ among the Dagomba, which is seen as a stage of physical and psychological transition in a woman's body and mind. A pregnant woman occupies ambivalent positions in 
Dagbon society. In one state, she is addressed as "a chief" and praised with appellations; in another context, she is bara (an ill person) due to physical and emotional stages which, in part, affect her ability to honor some relational responsibilities as well as physical labor. A participant stated the following:

In Dagbon, when a woman conceives, it brings joy to the entire family, and not only to the husband and wife. First, pregnancy informs everyone that the couple is healthy. Then to ensure that the woman carries the pregnancy to its end, she's told what to do and what not to do. There are some places she isn't supposed to go, and some things she is not allowed to do. She is cautioned against stealing, gossiping, etc. It is believed that these behaviors may get passed on to the unborn child. We even give her some native medicine to help her and the baby. And people must know that she's no longer a girl.

The pregnant woman goes through a rite known as par 'pirigibu (translated literally as 'undressing a woman'). The husband's sister (or cousin) performs rituals, including giving the pregnant woman a light knock on the head with an expression that says 'you were a child, but now you are an adult (woman)'. This ceremony is usually done around the fourth or fifth month of pregnancy to officially inform the woman that she is now in the state of pregnancy. Until this rite is performed, family members do not usually refer to her as a pregnant woman. This rite is carried out for married women during their first pregnancy (for other rites of passage among the Dagomba, see Abdul-Hamid, 2010). Pa? 'pirigtbu is never performed for any pregnancy outside marriage, which is referred to as a stolen one (zan ti pua or o zu pua). As an epistemic tradition, naming and shaming songs are part of the Dagomba ways of sanctioning their axiological perspectives. Historically, a shaming song could be composed around any woman who conceives outside marriage as a way of discouraging the behavior.

The relevance of the par 'pirigtbu ceremony is to prepare the pregnant woman psychologically, to withstand all the emotional, relational, and physical changes that come at different stages of pregnancy and childbirth. In most cases, gmanchee or kapiligu tim (indigenous medicine for gmanchee illness) is given to the woman to avert any difficulty or severe pains during delivery. Traditional medicines to protect the pregnant woman and the child from spiritual or evil beings are provided. The expectant mother reduces her household workload, adopts certain eating habits, avoids going to certain places, and/or partaking in some events, as noted in previous studies among the Dagomba (Bassoumah \& Adam, 2018; Dove, 2010; Imam, 2015). In this way, the pregnant woman lives in a state of harmony with herself, society, and the spiritual world until she is due for delivery. Similar practices around pregnancy are reported among the Kasena (Aborigo, Allotey, et al., 2015, Aborigo, Moyer, et al., 2012) and several other cultures in Africa, Asia, the Middle East (Raman et al., 2016). For instance, Raman et al. (2016) found that pregnancy was assumed as a special natural condition that linked the expectant mothers and the infant to the gods in Nigeria. The authors also noted that pregnancy at the early stages might be concealed or held in secrecy among some cultural groups in Liberia for fear of bewitchment.

\section{Male circumcision}

Other reproductive practices and rites continue after birth. When the newborn is a male, certain rituals are performed, and strict behavioral patterns are expected of the mother, especially with breastmilk. Further, male circumcision, likely rooted in Islamic influences, is a cherished reproductive practice among the Dagomba, occurring either on the day of birth or during the naming ceremony (eighth day after birth). For any reason, if the child is not circumcised within these days, circumcision is done before the boy reaches adolescence. Male circumcision is practiced in many countries for many reasons, including lowering the risk of sexual infections, cultural and religious acceptance, or identity (WHO, 2007).

\section{Breastmilk and the newborn child}

Lactating mothers, especially first-time mothers, are cautioned and mentored by TBAs and other experienced older women on how to take care of the baby, especially during breastfeeding. For the Dagomba, every woman who delivers is given a 40-day period within which she stays indoors and practices exclusive breastfeeding. After the 40th day, when the mother has ritually cleaned herself, she resumes a regular routine.

The Dagomba have cultural practices to increase breastmilk quantity in first-time mothers and those with low breastmilk. A TBA stated that “in Dagbon when a woman delivers and has low breastmilk, she's given milk" per the ritual of bihim nyuhubu (giving a lactating mother milk) by an indigenous specialist who goes to the house of the new mother at dawn to prepare a special drink for the mother. This practice involves a ritual where millet, cow milk, and other items are mixed according to a traditional recipe for the lactating mother to drink, which increases breastmilk production. Aborigo, et al. (2015), Aborigo, et al. (2012), and Hill et al. (2014) reported a similar practice among the Kasena-Nankana people. For instance, Hill et al. (2014) found that, when a lactating mother has limited breastmilk supply, a traditional recipe consisting of 'kaligongo' (local medicine) is mixed with 'yara mum' (flour from guinea corn) for the mother to drink which will make the breastmilk come.

Breastfeeding and breastmilk are essential components of RH and infants' healthy development, which carry cultural beliefs that demand precautions and strict behavioral practices by the mother (for further insights, 
refer to Seidu, 2013; Edwards, 2011). Participants stated that if a mother's breastmilk drops on the penis of the male child, the child's manhood will become dysfunctional and unable to reproduce in his adulthood. He may only function when the mother dies. This RH belief was described by an elderly participant below:

The breastmilk of a mother is very powerful. When a woman delivers a baby boy, she must be cautious when breastfeeding. When the breastmilk of a mother touches the boy's penis, that is it. You've lost it. It won't work until the mother dies. There is no treatment for that. Other forms of impotence can be treated, but not this. This illness is severe.

Connected to the above worldview is another RH lay theory, that, if a male child's urine drops in any cooked food and the mother eat the food, the result will be the same as her breastmilk dropping on the child's penis. Hence, the male child is to be covered very well during breastfeeding, when the mother is eating, or keeping leftover food for later use. Another belief, which applies to every infant, is that if breastmilk accidentally enters a child's ear, he/she may develop tibpong (rotten ear), medically known as otorrhea.

Tabong and Adongo (2013) reported similar spiritual views about the causes of infertility among women and men in the Upper East Region of Ghana, whereas Awedoba (2002) found that among the Kasena-Nankana, sex during early postpartum affects the quality of breastmilk and the infant health. All these beliefs and practices influence lactating mothers' behaviours regarding breastmilk and the consequences for non/observance of any cultural norms surrounding breastmilk.

\section{Sexuality and reproductive health illnesses}

Sexual promiscuity is a critical RH concern among the Dagomba, as several cultural illnesses are associated with sexuality (see Table 1). These illnesses, especially the first two, are among the major causes of mortality among Dagomba youth.

\section{Table 1: Common reproductive health illnesses among the Dagomba}

\begin{tabular}{|c|c|c|c|c|c|}
\hline Item & $\begin{array}{c}\text { The native name of } \\
\text { the illness }\end{array}$ & $\begin{array}{c}\text { Associated } \\
\text { modern medical } \\
\text { term }\end{array}$ & $\begin{array}{c}\text { Affected } \\
\text { sexual group }\end{array}$ & $\begin{array}{l}\text { Causation/ } \\
\text { source of } \\
\text { illness }\end{array}$ & Basic symptoms \\
\hline 1 & pa? 'kohingu & tuberculosis & both & $\begin{array}{l}\text { when a partner } \\
\text { coughs during } \\
\text { sexual } \\
\text { intercourse }\end{array}$ & $\begin{array}{l}\text { pale, grow lean, } \\
\text { persistent cough }\end{array}$ \\
\hline 2 & dapiri doro & - & both & $\begin{array}{c}\text { sexual } \\
\text { intercourse }\end{array}$ & - \\
\hline 3 & kpa? 'piclga & gonorrhea & males & $\begin{array}{l}\text { innate/sexual } \\
\text { intercourse }\end{array}$ & $\begin{array}{l}\text { itching or painful } \\
\text { sex organ and } \\
\text { whitish discharge }\end{array}$ \\
\hline 4 & gmanchee/kariligu & fibroid & females & $\begin{array}{l}\text { innate/sexual } \\
\text { intercourse }\end{array}$ & whitish discharge \\
\hline 5 & sompup ili & $\begin{array}{l}\text { dysmenorrhea or } \\
\text { menstrual pain }\end{array}$ & $\begin{array}{l}\text { matured } \\
\text { females }\end{array}$ & $\begin{array}{l}\text { innate to } \\
\text { women }\end{array}$ & $\begin{array}{l}\text { painful and irregular } \\
\text { menstrual flow }\end{array}$ \\
\hline
\end{tabular}

Source: Field data, 2015

Participants reported that pa? 'kohingu (translated as 'woman coughing') is an RH illness, which is caused when one partner or both partners cough(s) during sexual intercourse, as narrated below:

when you're with your wife (making love) and one of you coughs, you'll get pa?' kohingu, which can kill you unless you seek treatment for it. If you don't treat it and lie with another woman, that person will also get the illness.

The belief is that if pa? 'kohingu is not treated immediately (although TMPs claim they can heal it), it can be transmitted to others through sexual intercourse. Therefore, individual actions are required immediately due to the severity of physical, emotional, and psychological costs associated with the illness. Some traditional healers believe that this illness has similar symptoms as HIV/AIDS, and some healers even claimed it to be HIV. $P a$ ? 'kohingu is interpreted as tuberculosis by BMPs, although this label does not fit the cultural construct and lay knowledge of the Dagomba elders. 
DaPiri doro (translated as 'dirt or filth' illness) is another RH illness believed to have lethal effects. The word dapiri has two related meanings in the language: physical dirt/filth or spiritual dirt/contamination. It takes the second meaning as an illness and is reported as occurring when two men have intercourse with the same woman or when two women have intercourse with the same man who is not their husband. The cause of daPiri doro was explained as:

If you sleep with this woman and another man also sleeps with her, then the two of you have da?iri in you. You've a shared da?iri, a kind of spiritual contamination. When you are ill, and the other man visits you, the da?iri will be on you and worsen your health situation. It could kill you. Most of the youth today don't know that. And it kills them a lot. It's the same for women.

The above quote means that the two men or women have da? iri (shared spiritual contamination) in them since they have shared sexual fluid. It also implies that da? iri may not be an illness per se, but can worsen an existing ill-health. This disease is often related to men more than to women, given that polygamy (polygyny) is common among Dagomba.

Another related da? iri illness believed to be a cause of infant mortality is pakopicya (translated as "white widows'), a form of dapiri, which results when a woman loses her husband and has not gone through a spiritual cleansing ritual. Such a woman is believed to have da? iri within her, and, when she encounters a newborn baby, the da? iri in her can cause the baby's death. Therefore, as a preventive measure, every newborn is given both pakopicya and da? iri tim (traditional medicines) to protect them.

Although both pa? 'kohingu and dariri are RH illnesses, they have spiritual causations, which align with the general understanding of alaafee as transcending the physical. Based on the Dagomba worldview, the spiritual is ontologically linked with the material and the social worlds because religious life is inseparably interwoven with all life, as is the case in most part of Africa (Dube, 2009).

Spiritual dirt is likened to a poison that can cause death. It is also compared to physical dirt, which has the potency of causing several illnesses among humans. Similar RH views concerning sexual fluids and death have been reported in other Asian and African societies (Liddell et al., 2005; Raman et al., 2016). Blood, semen, vaginal secretions, and death are believed to be pollutants that have mythical powers within them, and are seen as the target of evil forces (Liddell et al., 2005). For example, Raman and colleagues (2016) reported that the Tibetans have a strong belief about the existence of ' $g r i b$ ', as a form of spiritual contamination associated with death, the blood of menstruation, and childbirth; a belief similar to the Hindu's concept of 'jutho' (ritual pollution). These observations resonate with the causal theories of pa? 'kohingu and da? iri illnesses among the Dagomba since they involved sexuality and death. The pollutants involved (sexual fluids and death) could be used by specific spiritual forces to penetrate the human system causing illnesses or death, underscoring the relevance of spirituality as an illness causal factor.

The remaining illnesses in Table 1 are well-known reproductive illnesses among Dagomba with less severe effects than the previously described conditions. Kpa?'piclga, gmanchee/ka? iligu, and sompup uli are illnesses related to body functioning and sexual hormones. The Dagomba theories of health and illness postulate that certain illnesses (kpaPa, chua, and dirigu) are innate, accordingly, part of everyone's creation or being (Bierlich, 2000; Kwame, 2016a; 2016b). Hence, kpa?'pielga, gmanchee/kariligu, and sompupuli relate to the generic kpara in the human system per the Dagomba illness aetiologies.

These illnesses (which we interpret as hormonal imbalances) relate to procreation. Therefore, their absence in a person could make conception and/or childbearing difficult. Conversely, in excesses, they become illness transmitted through sexual intercourse. These relate to barrenness among women, impotence among men, and other related sexual weakness/illnesses. Some of these illnesses, especially among men (i.e., male infertility and erectile dysfunction), do not have specific native emic terms. They are metaphorically expressed as: $O$ zug'talaa $n$-maai (his central brain is cold); $O$ zirila firiji (he is carrying a deep freezer); $O$ tooni bi kpuPra (his front does not rise); or O ku tooi mali pa?'bukaata (he can not solve a lady's problem).

\section{Traditional family planning practices}

Despite the safety, availability, and reliability of the modern FP methods, many sexually active people in developing countries do not use them (Cleland et al., 2006; Jaffre \& Suh, 2016). Helman (2007) asserts that, despite good intentions, modern contraceptives and FP methods are often unsuccessful in reducing population growth, because the idea of fertility regulation has either been rejected or has been reluctantly accepted in many parts of the world. Despite the availability, safety, and comprehensive knowledge about modern contraceptives and FP methods across many countries in West Africa, the unmet needs for contraceptives among couples and sexually active youth are high (Doctor et al., 2013; Etokidem et al., 2017; Staveteig, 2017).

Many couples use traditional RH and FP methods, as demonstrated earlier. This subsection discusses and reflects on Dagomba's traditional FP practices and associated cultural beliefs. 
One traditional way of regulating fertility and childbirth, according to the participants, is the practice of a woman going back to her parent's home to stay for a prolonged period (i.e., 2 to 4 years) after childbirth. The participants observed that, among the Dagomba, it is a common practice for a woman to move back to her family after her first or second childbirth. This practice, known as do?kuli (translated as 'give birth and go home'), permits the woman to stay away from the husband, so that her family can share in the joy by having time with her baby. It is also to offer her family the opportunity of being part of the child's up-bring in the early years. In addition to being a traditional FP method, it serves a secondary cultural function in marriage practices in Dagbon (Abdul-Hamid, 2010). Although this cultural practice is still ongoing, amongst most urban Dagbon and among many couples, the length of stay has reduced considerably. A similar pattern exists among the Kasena people (Awedoba, 2002) as a child birth-spacing method.

Other known traditional FP practices among Dagomba identified by participants included prolonged breastfeeding, postpartum abstinence, pre-marital abstinence, and knowledge of the ovulation cycle (rhythm method). Traditionally, extended breastfeeding was used as the most common way of regulating childbirth and spacing among couples. Participants noted that, culturally, a woman needs to breastfeed the child for not less than two years before giving birth to the next child. Connected to prolonged breastfeeding is postpartum abstinence, in which some participants indicated that sexual intercourse might change the taste of breastmilk, which may impact the infant's development. Many lactating mothers abstain from sex until the child is at least two years, which is managed by the woman returning to her parent's home or living with her husband's mother. Nevertheless, urbanization, globalization, and increased literacy and formal education have impacted this practice.

Despite the changing trends in the use of these methods, many of these practices have been identified among the Kasena (Adongo et al., 1997; Awedoba, 2002), among the Kanuri of Northeastern Nigeria (Mairiga et al., 2012), among childbearing women in Kano (Rabiu \& Rufai, 2018), among the Yoruba of Southwestern Nigeria (Jinadu \& Ajuwon, 1997; Jinadu et al., 1997), among the Mossi of Burkina Faso (Rossier \& Hellen, 2014), and many other cultures in Asia (Raman et al., 2016). In a study on the use of traditional and modern FP methods, Ajayi et al. (2018) found that of the $66.1 \%$ of childbearing women who use any form of contraceptives and FP methods, $44.3 \%$ used traditional methods, including withdrawal, abstinence, rhythm, and lactation amenorrhea.

To encourage postpartum abstinence among the Dagomba, there is a belief known as bia zugu ya?ibu (sex after childbirth), which requires that after a woman gives birth, only the husband can have intercourse with her without any harm to the child. A lactating mother who has coitus with another man (bia zugu ya? ibu) during this period will cause her child's death when her husband later lies with her (because of da? iri, as previously discussed). This belief promotes abstinence among women, in addition to the practice of breastfeeding, especially if they are living away from their husbands for prolonged periods. This gendered belief functions as a form of social control on women to prevent extramarital affairs.

Pre-marital abstinence was another traditional FP method noted by the participants. This practice was argued to help young boys and girls stay away from sex until they are mature enough to bear pregnancy and childbirth responsibilities. A female participant spoke on pre-marital abstinence:

A girl who experiences her menses for the first time was given some training on managing the menstrual flow. She's also warned seriously not to go closer to males since she's matured and could become pregnant, which could bring shame to herself and her family.

Pre-marital abstinence has been an area of RH challenge. Participants lamented that teenage pregnancy, which was shameful in the past, is now common in Dagbon society. Some participants attributed these changes to current child upbringing practices. In contrast, others attributed this shift to various factors, such as the gradual breakdown of the extended family system, formal education, global entertainment, fashion, and the film industries.

Knowledge of the ovulation cycle (the rhythm or calendar method) was identified as another traditional Dagomba FP practice. The belief is that a woman is "impure" during her menstrual period, and no man should go closer to her, but a few days after the menstrual period are "so-called" free days. This knowledge was used as an FP method, where the couple knows the menstrual cycle as described by one participant:

Our fathers said every woman has two gourds (implying ovaries), one to each breast. When one gourd is formed, it begins to come down to the womb. At a point, it'll stay waiting for a male (the male semen). If it doesn't get it, it'll harden and burst. At that moment, the woman will get her menses. As the blood flows, it's waiting for the other gourd to form. We're told it could take 4-7 days. So, you start counting from the day the blood stops. Within those days, you can be with your wife, and nothing will happen. But on the $7^{\text {th }}$ and $8^{\text {th }}$ days after the flow, you must be careful. By this period, the other gourd is formed. If you don't want disgrace, you must stay away from her.

This narrative shows how knowledge about the menstrual cycle of a woman is used as an FP method. It further emphasized oral means as the traditional way of knowledge transmission among the Dagomba. This finding confirms the 2014 Demographic Health Survey (DHS) report, which indicated that, in Ghana, over $70 \%$ of 
all women and men (whether currently married or sexually active) know about traditional FP methods, which included the rhythm and withdrawal methods (GSS, GHS, \& ICF International, 2015). This statistic shows the relative importance or popularity of these traditional FP methods, and underscores the fact that this knowledge is in use, regardless of modern contraceptives' availability. Staveteig (2017, p. 15) argued that apart from underreporting use of the rhythm and withdrawal methods in most survey data, intentional use of prolonged abstinence, especially during the postpartum period to space births, is often omitted in such data.

\section{Health implications}

Traditional knowledge of $\mathrm{RH}$ perceptions and practices among the Dagomba have important implications for healthcare professionals and the healthcare system related to maternal and child health, $\mathrm{RH}$ and fertility regulation, and preventive health practices. Exploring traditional $\mathrm{RH}$ values is particularly essential as modern contraceptives and FP methods are not highly utilized in Ghana (Kyilleh et al., 2018; MOH, 2015).

Dagomba knowledge, beliefs, and practices surrounding breastfeeding and breastmilk are one area of critical focus and opportunity. Attention should be given to breastfeeding since a number of reproductive health benefits and risks are associated with it among the Dagomba. Traditional practices surrounding breastfeeding are observed to be important in many cultures with the support of relatives, partners, and the wider community deemed crucial for successful breastfeeding (Aborigo, Moyer, et al., 2012; Barnett, 2015; Hill et al., 2014; Seidu, 2013). Barnett (2015) further noted that customs, such as having the mother and child live with family (away from the husband) post-partum, enables this crucial dyad to rest, bond, and establish healthy breastfeeding practices.

Breastfeeding is not only an excellent FP method (prolonged breastfeeding helps in the spacing of children), but it also helps to provide the nutritional needs of infants, which health experts, child nutritionists, and other international organizations (UNICEF and UNESCO) encourage (Barnett, 2015; World Alliance for Breastfeeding Action [WABA], 2014). Breastmilk is acclaimed worldwide for its protective values for both nursing mothers and their infants. Breastfeeding reduces the risk of breast cancer among women. Furthermore, breastmilk is known to provide essential nutrients to the newborns and prevent certain illnesses, even in later life; thus, the WABA (2014) declared: "Breastfeeding: a winning goal for life" (from website).

The Dagomba traditional practice for increasing breastmilk among lactating mothers, a practice observed among other cultures, could impact prolonged and exclusive breastfeeding. When this practice is encouraged, it can complement the six months exclusive breastfeeding initiative advocated by health experts as key in helping to reduce malnutrition among infants (WABA, 2014).

Circumcision among Dagomba, as a reproductive health practice among males, is believed to have health benefits in this era of increasing sexual infections, as research has shown that male circumcision has the advantage of reducing the rate of sexual infections, including HIV/AIDS (WHO, 2007). Nonetheless, female circumcision, which is cherished among some cultures, is reported to have many negative health consequences on women.

Moreover, the traditional knowledge and theories associated with RH illnesses, especially pa? 'kohingu and da? iri doro, emphasize that some illnesses have spiritual causal explanations. The caution against sexual promiscuity among people, especially the youth, as a preventive health lens, can potentially reduce the rate of sexually transmitted infections, including HIV/AIDS and Hepatitis B. When the Dagomba knowledge and practices are examined and discussed broadly, the health benefits can be vast. This knowledge can be integrated into organized health talks by medical practitioners in the formal health system and other organizations working on public health and RH campaigns. Sexual promiscuity, which is frowned upon among different cultures in Northern Ghana (Awedoba, 2002), requires more than an abstinence agenda for the youth.

Furthermore, when health experts demonstrate knowledge of traditional $\mathrm{RH}$ practices and communicate it, it reflects sensitivity to culture, traditions, and beliefs as valued practices. As a result, some traditional $\mathrm{RH}$ and FP methods should be encouraged during antenatal and postnatal counseling sessions. Midwives and nurses who provide information and knowledge about modern contraceptives and FP methods should first begin with, or enquire from childbearing women and the sexually active youth, what methods they know and have been using, before adding the complexities of modern interventions. As Jaffre and Suh (2016, p. 177) rightly said, "the use of contraceptive methods depends on wanting, knowing, and being able to use them". Moreover, Hill et al. (2014) and Raman et al. (2016) emphasized the need to understand the value of culture, traditional beliefs, and values in women uptake of modern contraceptives and FP methods.

When biomedical experts learn and share the relevant traditional practices to the public, acknowledging diversity in the medical models, illness representation, and cultural sensitivity in health may impact the uptake of many healthcare services (Helman, 2007). Also, by taking note of the traditional RH and FP practices, health professionals can identify the "harmful" traditional practices around pregnancy, delivery, and breastfeeding, and dialogue with the practitioners of such traditions for a change. The negative perceptions and the limitations of 
the modern FP methods can be addressed during those dialogues. Thus, the relevance of cultural sensitivity in promoting healthcare outcomes is imperative to move forward together (Samovar et al., 2010).

Besides, knowledge of traditional FP practices, which are culturally sensitive and valued among different ethnic groups in Ghana, need to be evaluated and encouraged alongside the modern ones. The methods of prolonged breastfeeding, post-partum abstinence, and pre-marital abstinence can promote maternal and child health, and fertility regulation in Ghana and elsewhere. Traditional FP methods, when critically examined and advocated for by health professionals, can complement the modern ones, as there is some stagnation in the use of contemporary contraceptives which has been accompanied by an increase in the unmet needs of women for FP in Ghana (GSS, GHS, \& ICF International, 2015; MOH, 2011; 2015; Staveteig, 2017).

Nonetheless, most healthcare professionals are likely to dismiss traditional knowledge, beliefs, and practices, as presented above. They will either label them as 'inferior', 'backward', or utterly ineffective because they are traditional methods. But as Helman (2007, p. 81) argued, these "traditional methods are deeply trusted, valued, and practiced by members of societies who have them". Cultural norms, perceptions, beliefs, and practices that guide sexual behaviors and sexuality need to be approached with sensitivity and humility. One of the factors influencing modern FP methods and contraceptives is based on the knowledge people have about them. Therefore, it would be logical to start with what people know, believe in, and have used for ages, and then add those they do not understand to their unique knowledge set.

\section{Conclusion}

This study investigated the Dagomba traditional $\mathrm{RH}$ practices and the beliefs and values that inform those practices. The study found that, among the Dagomba, the concepts of RH and FP are not only related to sexual activity, but also extend across the life continuum. The Dagomba perspectives on RH practices start at pregnancy and intensify during the early years of a child's life, through to their adulthood. The rites associated with pregnancy and breastfeeding have direct health implications for maternal and child health and must be given attention.

While the findings of this study cannot be generalized across the entire country since the experiences, practices, and beliefs are limited to the Dagomba, nonetheless the reported results confirm similar practices across several cultural groups in Ghana and in other countries. Another limitation is that our study did not explore the current usage of many traditional RH and FP practices among the participants. Moreover, increasing literacy rates, urbanization, and modernization might have impacted the operationalizing of some of the cultural practices noted in the study.

Still, many traditional RH and FP practices among the Dagomba are relevant in modern health contexts. Accordingly, health experts should strive to understand these conventional RH beliefs and practices and incorporate this cultural/traditional knowledge into their professional practices, programs, and services as potentially complementary strategies. 


\section{References}

Abdul-Hamid, M. (2010). The influence of Islam on an African people:: The case of the Dagomba of Northern Ghana. The International Conference on Universalism, Relativism, \& Intercultural Philosophy. The University of Cape Coast, 3-5 Feb, 2010 (pp. 1-25). Cape Coast: Academia.edu Weekly Digest.

Aborigo, R. A., Allotey, P., \& Reidpath, D. D. (2015). The traditional healer in obstetric care: A persistent wasted opportunity in maternal health. Social Science \& Medicine, 133, 59-66. doi: 10.1016/j.socscimed.2015.03.046

Aborigo, R. A., Moyer, C. A., Rominski, S., Adongo, P., Williams, J., Logonia, G., Affah, G., Hodgson, A., \& Engmann, C. (2012). Infant nutrition in the first seven days of life in rural northern Ghana. BMC Pregnancy and Childbirth, 12(76). http://www.biomedcentral.com/1471-2393/12/76

Adongo, P. B., Phillips, J. F., Kajihara, B., Fayorsey, C., Debpuur, C., \& Binka, F. N. (1997). Cultural factors constraining the introduction of family planning among the Kasena-Nankana of Northern Ghana. Social Science \& Medicine, 45(12), 1789-1804.

Ajayi, A. I., Adeniyi, O. V., \& Akpan, W. (2018). Use of traditional and modern contraceptives among childbearing women: Findings from a mixed-methods study in two southwestern Nigerian states. BMC Public Health, 18(604), 1-9. doi:10.1186/s12889-018-5522-6

Akafuah, R. A., \& Sossou, M.-A. (2008). Attitudes towards and use of knowledge about family planning among Ghanaian men. International Journal of Men's Health, 72), 109-120. doi:10.3149/jmh.0702.109

Awedoba, A. K. (2002). Kasena norms and reproductive health. Research Review NS, 18(1), 13-26.

Barnett, I. (2015, August 4). Breastfeeding is a human right, but does society truly enable women to breastfeed? Retrieved August 26, 2015, from 50.50 inclusive democracy: www.opendemocracy.net/5050/inkabarnett

Bassoumah, B. \& Adam, M. A. (2018). Indigenous maternity caregiving practices: Implications for maternal, foetal, and neonatal health in Northern Ghana. JUMMEC, 21(1), 32-38.

Bawah, A. A., Akweongo, P., Simmons, R., \& Phillips, J. F. (1999). Women's fears and men's anxieties: The impact of family planning on gender relations in Northern Ghana. Studies in Family Planning, 301), 54-66.

Berhane, A., Amberbir, A., Morankar, S., Berhane, A., Deribe, K., \& Biadgilign, S. (2011, December 4). Men's knowledge and spousal communication about modern family planning methods in Ethiopia. African Journal of Reproductive Health, 15, 24-32.

Bertrand, T. J., Mangani, N., Mansilu, M., \& Landry, G. E. (1985, Nov/Dec). Factors influencing the use of traditional versus modern family planning methods in Bas Zaire. Studies in Family Planning, 16(6), 332337. doi:129.242.210.6

Bierlich, B. (2000). Injection and the fear of death: An essay on the limits of biomedicine among the Dagomba of Northern Ghana. Social Science \& Medicine, 50, 703-713.

Bove, R. \& Valeggia, C. (2009). Polygyny and women's health in sub-Saharan Africa. Social Science \& Medicine, 68, 21-29. doi:10.1016/j.socscimed.2008.09.045

Bowling, A. (2009). Research methods in health: Investigating health and health services (3rd ed.). New York: McGraw Hill, Open University Press.

Braun, V. \& Clarke, V. (2006). Using thematic analysis in psychology. Qualitative Research in Psychology, 3(2), 77-101. doi:10.1191/1478088706qp063oa

Clarke, V. \& Braun, V. (2013). Teaching thematic analysis: Overcoming challenges and developing strategies for effective learning. The Psychologist, 26(2), 120-123.

Cleland, J., Bernstein, S., Ezah, A., Faundes, A., Glasier, A., \& Innis, J. (2006, November 18). Family planning: the unfinished agenda. Sexual and Reproductive Health, 368(3), 1810-1827. doi:10.1016/S01406736(06)69480-4

Cox, M. C., Hindin, J. M., Otupiri, E. \& Larsen-Reindorf, R. (2013, December 4). Understanding couples' relationship quality and contraceptive use in Kumasi, Ghana. International Perspectives on Sexual and Reproductive Health, 39, 185-194. doi:10.1363/3918513

Craymah, J. P., Oppong, R. K., \& Tuoyire, D. A. (2017). Male involvement in maternal health care at Anomabo, Central Region, Ghana. International Journal of Reproductive Medicine. 1-8. doi:10.1155/2017/2929013 
Doctor, H. V., Findley, S. E., Afenyadu, G. Y., Uzondu, C., \& Ashir, G. M. (2013). Awareness, use, and unmet need for family planning in rural Northern Nigeria. African Journal of Reproductive Health, 174), 107-117.

Dove, N. (2010). A return to traditional healthcare practice: A Ghanaian study. Journal of Black Studies, 40(5), 823-834. doi:10.1177/0021934708320001

Dube, W. M. (2009). 'I am because we are': Giving primacy to African indigenous values in HIV/AIDS prevention. In M. F. (ed.), African ethics: An Anthology of Comparative and Applied Ethics (pp. 188--217). University of Kwazulu-Natal Press.

Durowade, K. A., Omokanye, L. O., Elegbede, O. E., Adetokunbo, S., Olomofe, C. O., Ajiboye, A. D., Adeniyi, M. A., \& Sanni, T. A. (2017). Barriers to contraceptive uptake among women of reproductive age in a semiurban community of Ekiti State, Southwest Nigeria. Ethiopian Journal of Health Science, 271), 121-128. doi: 10.4314 /ejhs.v27i2.4

Edwards, R. (2011). Herbs and healers of the North: Medicine, practices, and philosophies in Islamic and Traditional healing in Northern Ghana. Independent Study Project (ISP) Collection, Paper 1250. Retrieved June 5, 2016, from www.digitalcollections.sit.edu/isp_collection/1250

Etokidem, A. J., Ndifon, W., Etowa, J., \& Asuquo, E. F. (2017). Family planning practices of rural community dwellers in Cross River State, Nigeria. Nigerian Journal of Clinical Practice, 20, 707-715. doi:10.4103/njcp.njcp_193_15

Gauvin, L., \& Belanger-Gravel, A. (2017). Behavioural theories and building promotion interventions: Persistent challenges and emerging perspectives. In I. P. Rootman, Health Promotion in Canada (4th ed., pp. 6783). Toronto: Canadian Scholars.

Ghana Health Service. (2010). The health sector in Ghana: Facts and figures. Accra, Ghana: Ministry of Health. www.moh-ghana.org

Ghana Statistical Services [GSS], Ghana Health Service [GHS], and ICF International. (2015). Ghana demographic and health survey 2014. Maryland, USA: Rockville. www.DHSprogram.com

Ghana Statistical Services. (2013). 2010 Population and Housing Census: Regional Analytical Report, Northern Region. Accra: Government of Ghana.

Gupta, M. L., Aborigo, R. A., Adongo, P. B., Rominskia, S., Hodgson, A., Engmanne, C. M., \& Moyer, C. A. (2015). Grandmothers as gatekeepers? The role of grandmothers in influencing health-seeking for mothers and newborns in rural northern Ghana. Global Public Health, 109), 1078-1091. doi: $10.1080 / 17441692.2014 .1002413$

Gyekye, K. (1996). 2010 population and housing census: Regional analytic report. Accra, Ghana: Sankofa Publishing Company.

Helman, G. C. (2007). Culture, health and illness (5th ed.). London: Hodder Education.

Hill, E., Hess, R., Aborigo, R. A., Adongo, P., Hodgson, A., Engmann, C., \& Moyer, C. A. (2014). “I don' t know anything about their culture": The disconnect between allopathic and traditional maternity care providers in rural Northern Ghana. African Journal of Reproductive Health, 18(2), 36-45.

Homsy, J., King, R., Tenywa, J., Kyeyune, P., Opio, A., \& Balaba, D. (2004). Defining minimum standards of practice for incorporating African traditional medicine into HIV/AIDS prevention, care, and support: A regional initiative in Eastern and Southern Africa. The Journal of Alternative and Complementary Medicine, 105), 905-910.

Imam, A. H. (2015). Change and cultural survival in Dagbon: Assessing the influence of Islam on aspects of Dagbamba cultural practices. International Journal of Innovative Research and Advanced Studies (IJIRAS), 2(1), 28-37.

Jaffre, Y., \& Suh, S. (2016). Where the lay and the technical meet: Using an anthropology of interfaces to explain persistent reproductive health disparities in West Africa. Social Science \& Medicine, 156, 175-183. doi: 10.1016/j.socscimed.2016.03.036

Jinadu, M. K., \& Ajuwon, B. (1997). Traditional fertility regulation methods among the Yoruba of Southwestern Nigeria: II. A prospective study of use-effectiveness. African Journal of Reproductive Health, 1(1), 6573. 
Jinadu, M. K., Olusi, S. O., \& Ajuwon, B. (1997). Traditional fertility regulation among the Yoruba of Southwestern Nigeria: I. A study of prevalence, attitudes, practice, and methods. African Journal of Reproductive Health, 56-64.

Kleinman, A. (1980). Patients and healers in the context of culture: An exploration of the borderland between Anthropology, Medicine, and Psychiatry. London: University of California Press.

Kwame, A. (2016a). Theorizing health and illness: The role of language and secrecy in traditional healing among the Dagomba. International Journal of Humanities and Social Science, 6(2), 73-83.

Kwame, A. (2016b). Traditional medicine and healing among the Dagomba of Ghana. MPhil Thesis. The Arctic University of Norway. Tromso.

Kyilleh, J. M., Tabong, P. T.-N., \& Konlaan, B. B. (2018). Adolescents' reproductive health knowledge, choices, and factors affecting reproductive health choices: A qualitative study in the West Gonja District in the Northern Region, Ghana. BMC International Health and Human Rights, 18(6), 1-12. doi:10.1186/s12914018-0147-5

Lacey, A. \& Luff, D. (2009 [2001]). Qualitative data analysis. Sheffield: Trent Focus.

Liddell, C., Barrett, L., \& Bydawell, M. (2005). Indigenous representation of illness and IADS in Sub-Saharan Africa. ELSEVIER: Social Science \& Medicine, 60, 691-700.

Mairiga, A. G., Garba, A., Kullima, A., \& Bako, B. (2012). The practice of traditional family planning among rural Kanuri communities of Northeastern Nigeria. International Journal of Biological \& Medical Research, 3(1), 1277-1280.

Miles, M. B., Huberman, A. M. \& Saldana, J. (2013). Qualitative Data Analysis (3rd ed.). Los Angeles: Sage.

Ministry of Health. (2011). The 2011 Health Summit Report. Accra, Ghana: Ministry of Health.

Ministry of Health. (2015). The 2014 Holistic Assessment of the Health Sector Programme of Work. Accra, Ghana: Ministry of Health. www.moh-ghana.org

Moyer, C. A., Adongo, P. B., Aborigo, R. A., Hodgson, A., Engmann, C. M., \& DeVries, R. (2014). ' 'It's up to the woman's people'': How social factors influence facility-based delivery in rural Northern Ghana. Maternal and Child Health Journal, 18, 109-119. doi:10.1007/s10995-013-1240-y

Mutiba-Ngoma, C. a. (2010, March). Knowledge and use of modern family planning methods by rural women in Zambia. Curationis, 33(1), 17-22. doi:Curationis 33(1): 17-22.

Ofosu-Amaah, S. (2005). Health and disease in Ghana: The origins of disease and the future of our health.. Accra: Ghana Academy of Arts and Sciences.

Opoku, B. \& Kwaununu, F. (2011). Knowledge and practices of emergency contraceptives among Ghanaian women. African Journal of Reproductive Health, 15, 147-152.

Rabiu, A., \& Rufai, A. A. (2018). The role of traditional contraceptive methods in family planning among women attending primary health care centers in Kano. Annals of African Medicine, 174), 189-195. doi:10.4103/aam.aam_60_17

Raman, S., Nicholls, R., Ritchie. J., Razee, H., \& Shafiee, S. (2016). How natural is the supernatural? Synthesis of the qualitative literature from low and middle-income countries on cultural practices and traditional beliefs influencing the perinatal period. Midwifery, 39, 87-97. doi:10.1016/j.midw.2016.05.005

Rossier, C., \& Hellen, J. (2014). Traditional birth spacing practices and uptake of family planning during the postpartum period in Ouagadougou: Qualitative results. International Perspectives on Sexual and Reproductive Health, 402), 87-94. doi: 10.1363/4008714

Samovar, L. A., Porter, R. E., \& McDadiel, E. R. (2010). Communication between cultures (7th ed.). Boston: Wadsworth Cengage Learning.

Seidu, I. (2013). Exclusive breastfeeding and family influence in rural Ghana: A quantitative study. Malmo: Malmo University.

Staveteig, S. (2017). Fear, opposition, ambivalence, and omission: Results from a follow-up study on unmet need for family planning in Ghana. PLoS ONE 12(7): e0182076., 12(7:e0182076), 1-28. doi: 10.1371/journal.pone.0182076 
Tabong, P. T.-N., \& Adongo, P. B. (2013). Understanding the social meaning of infertility and childbearing: A qualitative study of the perception of childbearing and childlessness in Northern Ghana. PLoS ONE, $8(1:$ :54429), 1-9. doi: 10.1371/journal.pone.0054429

Tonah, S. (2012). The politicization of a chieftaincy conflict: The case of Dagbon, Northern Ghana. Nordic Journal of African Studies, 21(1), 1-20.

WABA. (2014, August 1-7). World breastfeeding week on the theme; "Breastfeeding: a winning goal for life." World Alliance for Breastfeeding Action: www.waba.org.my

World Health Organization. (2003). Profile of reproductive health situation in Ghana. WHO.

World Health Organization. (2007). Male circumcision: Global trends and determinants of prevalence, safety, and acceptability. WHO. 